\title{
OPEN Efficacy and side effects of bio-fabricated sardine fish scale silver nanoparticles against malarial vector Anopheles stephensi
}

Kadarkarai Murugan $^{1 凶}$, Jayapal Subramaniam $^{1}$, Rajapandian Rajaganesh ${ }^{1}$, Chellasamy Panneerselvam², Pandiyan Amuthavalli ${ }^{1}$, Murugan Vasanthakumaran ${ }^{3}$, Sudalaimani Jayashanthini ${ }^{1}$, Devakumar Dinesh ${ }^{1}$, Jaganathan Anitha ${ }^{1}$, Lan Wang ${ }^{4}$, Jiang-Shiou Hwang ${ }^{5,6,7 凶}$, Hans-Uwe Dahms ${ }^{8,9,10}$, Sunaina Mudigonda ${ }^{8,11}$ \& Al Thabiani Aziz ${ }^{2}$

Mosquitoes are a great menace for humankind since they transmit pathogenic organisms causing Malaria, Dengue, Chikungunya, Elephantiasis and Japanese encephalitis. There is an urgent need to discover new and novel biological tools to mitigate mosquito-borne diseases. To develop bioinsecticides through newly developed nanotechnology is another option in the present research scenario. In this study we synthesize and characterize sardine fish scales with silver nitrate by adopting various instrumental techniques such as UV- and FTIR-spectroscopy, energy-dispersive X-ray (EDAX), X-ray diffraction analyses (XRD) and scanning electron microscopy (SEM). Toxicity bioassays were conducted with young developmental stages of mosquito vectors. Significant mortality appeared after different life stages of mosquito vectors (young larval and pupal instars were exposed to the nanomaterials). $L C_{50}$ values were $13.261 \mathrm{ppm}$ for young first instar larvae and $32.182 \mathrm{ppm}$ for pupae. Feeding and predatory potential of $G$. affinis, before and after exposure to nanoparticles against mosquito larval (I \& II) instars of the mosquitoes showed promising results in laboratory experiments. Feeding potential of mosquito fish without nanoparticle treatment was $79.7 \%$ and $70.55 \%$ for the first and second instar larval populations respectively. At the nanoparticleexposed situation the predatory efficiency of mosquitofish was $94.15 \%$ and $84.3 \%$, respectively. Antioxidant enzymes like (SOD), (CAT), and (LPO) were estimated in the gill region of sardine fish in control and experimental waters. A significant reduction of egg hatchability was evident after nanoparticle application. It became evident from this study that the nano-fabricated materials provide suitable tools to control the malaria vector Anopheles stephensi in the aquatic phase of its life cycle. This finding suggests an effective novel approach to mosquito control.

Malarial fever is the most important infectious disease around the tropical belt worldwide. Several biotic and abiotic factors favour the spread of this disease ${ }^{1}$. The mosquito species Anopheles stephensi is transmits the protozoan parasite Plasmodium falciparum that causes malaria and this provides severe problems in Asian countries ${ }^{2,3}$

\footnotetext{
${ }^{1}$ Division of Entomology, Department of Zoology, School of Life Sciences, Bharathiar University, Coimbatore, Tamil Nadu 641046, India. '2Department of Biology, Faculty of Science, University of Tabuk, Tabuk 71491, Saudi Arabia. ${ }^{3}$ Department of Zoology, Kongunadu Arts and Science College, Coimbatore 641029, India. ${ }^{4}$ School of Life Science, Shanxi University, Taiyuan 030006, Shanxi, China. ${ }^{5}$ Institute of Marine Biology, National Taiwan Ocean University, Keelung 20224, Taiwan. ${ }^{6}$ Center of Excellence for Ocean Engineering, National Taiwan Ocean University, Keelung 20224, Taiwan. ${ }^{7}$ Center of Excellence for the Oceans, National Taiwan Ocean University, Keelung 20224, Taiwan. ${ }^{8}$ Department of Biomedical Science and Environmental Biology, Kaohsiung Medical University, Kaohsiung 80424, Taiwan. ${ }^{9}$ Research Center for Environmental Medicine, Kaohsiung Medical University, Kaohsiung City 807, Taiwan. ${ }^{10}$ Department of Marine Biotechnology and Resources, National Sun Yat-Sen University, Kaohsiung City 804, Taiwan. ${ }^{11}$ Department of Medicinal and Applied Chemistry, Kaohsiung Medical University, Kaohsiung City 807, Taiwan. ${ }^{\circledR}$ email: kmvvkg@gmail.com; jshwang@mail.ntou.edu.tw
} 


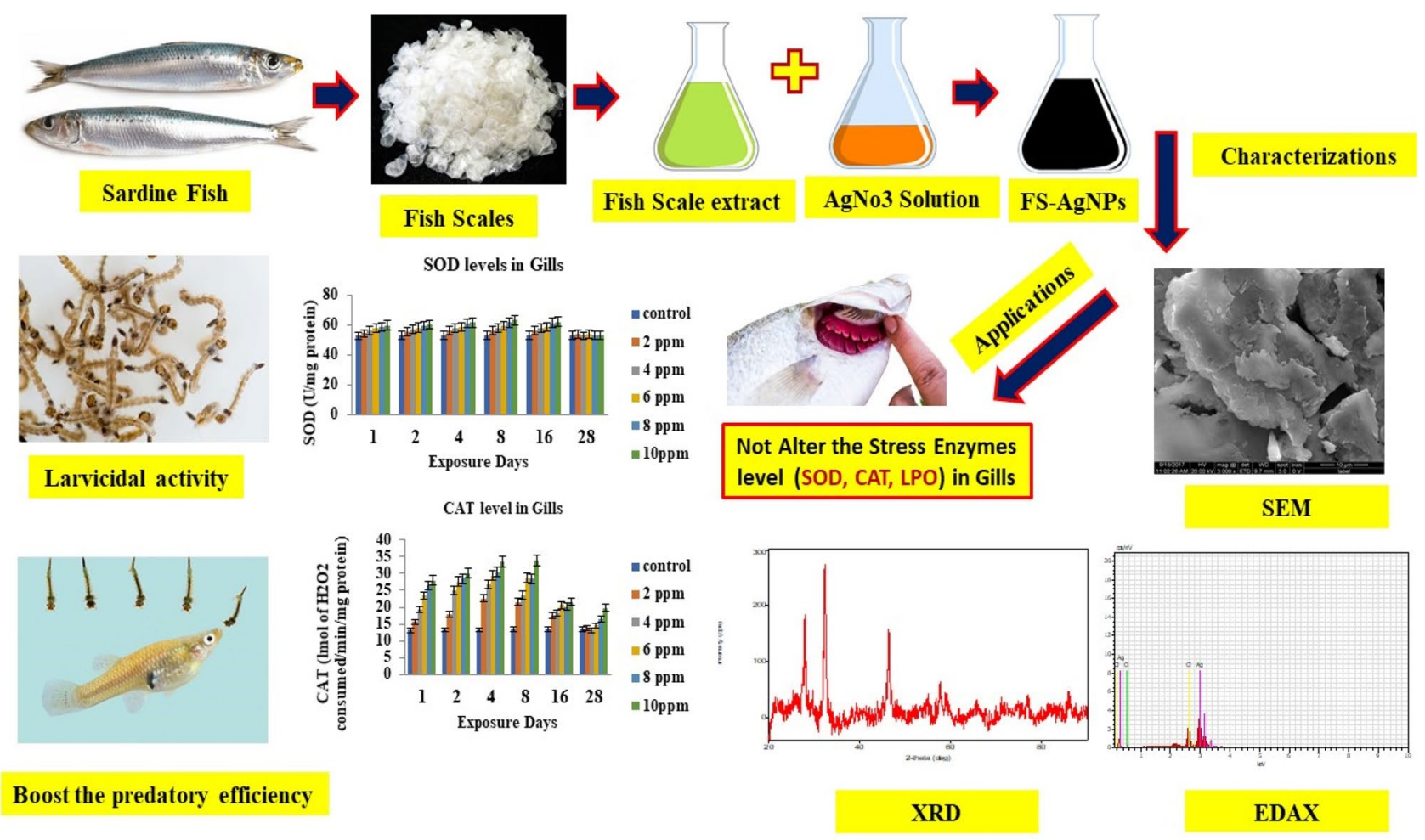

Figure 1. Pictorial representations of the salient steps of this study.

as well as elsewhere in the tropics. Allelochemicals (plant secondary metabolites) are a rich source of biologically active molecules' which are important for Ayurveda, Unani, Siddha medicines and other therapeutic systems ${ }^{4,5}$. In this study, we prepared an eco-friendly mode and silver nanoparticles from fish scale extract acting as a reducing/stabilizing agent. Other abiotic parameters like temperature, $\mathrm{pH}$ on the quantification of the materials on the biosynthesis of silver nanoparticles were investigated ${ }^{6}$. Nowadays, silver nanomaterials show a variety of biological activities against microbial technology and nanomedical applications ${ }^{7,8}$. So, AgNP has several different medical uses and it has several potential uses in the field of $\operatorname{cosmetics}^{9}$ which includes mosquito vector control ${ }^{10-12}$. Generally, silver-nanoparticles are widely used for microbe suppression programs, hence, it can be employed for the control of medical problems $s^{13,14}$. For integrated vector control programs in aquatic systems, biocontrol through predation provides an important regulation tool within ecosystems ${ }^{15,16}$. Predatory fishes are commonly employed for mosquito larval control in cultivated paddy fields, wetlands, as well as aquaculture ponds ${ }^{17,18}$.

A detailed investigation was made by Murugan et al. ${ }^{19}$ on the predatory behavior of gold NPs and guppies against young larval instars of mosquitoes. Due to the negative impacts of insecticidal synthetic chemicals on the environment, we have investigated the toxicological, ecological and physiological status of animals and their mode of action being of paramount importance ${ }^{20,21}$. Enzymes are involved in regulating the biological functions of living organisms $\mathrm{s}^{22,23}$. Environmental contaminants might affect metabolic and physiological processes at the same time they form residues which are absorbed in different tissues of water-dwelling organisms, including fishes ${ }^{24}$. Pollutants commonly accumulate in the tissues and organs such as in the liver, gill and blood tissues. Pollutants are the main causes of stress to particular organisms and fish have the ability to regulate metals to cope with temperature tolerance and to prevent toxic effects on the organisms. Furthermore, fish have innate mechanisms to detoxify toxic chemicals. In fish the gills are pivotal organs and perform various physiological activities such as respiration, acid-base regulation and nitrogenous waste elimination. To prevent ROS-mediated cellular damage, organisms generally activate antioxidant defense systems ${ }^{25,26}$. These include the two major enzymatic profile groups superoxide dismutase (SOD) and catalase (CAT) which are the most sensitive enzyme groups for free radical scavenging processes ${ }^{3,27}$. Damages caused by ROS are provided by lipid membrane oxidation and lipid peroxidation $(\mathrm{LPO})^{23,28}$. Livingstone et al. ${ }^{29}$ studied various contaminants exposed to the production and oxidative damage in aquatic organisms. The toxicity, behavior and fate of nano-pesticides were less investigated ${ }^{30,31}$.

In this paper, we used bio-fabricated silver nanomaterials from fish scales (Fig. 1). These materials were nano-characterized by adopting various instrumentation techniques for the following issues: (i) Toxicity effect of biosynthesized fish scale-nanomaterials on the larvae and pupae of An. stephensi and also studied the life history performance and ovicidal effect; (ii) predatory potential of fish on mosquito larvae in contaminated environments; (iii) impact of bio-fabricated fish nanomaterials on the concentrations of superoxide dismutase, catalase and lipid peroxidase enzymes in the gill region of the teleost fish G. affinis. 


\begin{tabular}{|l|c|c|c|l|l|}
\hline & & \multicolumn{2}{|l|}{$\mathbf{9 5 \%}$ confidence limit $\mathbf{L C}_{\mathbf{5 0}}\left(\mathbf{L C}_{\mathbf{9 0}}\right)$} & & \\
\cline { 3 - 4 } Larval instars & $\mathbf{L C}_{\mathbf{5 0}}\left(\mathbf{L C}_{\mathbf{9 0}}\right)$ & Lower & Upper & Regression equation & $\chi^{2}($ d.f. $=\mathbf{4})$ \\
\hline 1st instar & $80.923(173.939)$ & $71.804(157.103)$ & $89.418(198.695)$ & $y=1.115+0.014 x$ & 0.819 n.s. \\
\hline 2nd instar & $102.623(224.472)$ & $91.768(195.184)$ & $115.116(273.433)$ & $y=1.079+0.011 x$ & 0.818 n.s. \\
\hline 3rd instar & $151.609(344.288)$ & $129.004(269.691)$ & $197.958(521.433)$ & $y=1.008+0.007 x$ & 0.016 n.s. \\
\hline 4th instar & $170.382(336.187$ & $146.134(269.395)$ & $218.930(481.779)$ & $y=1.317+0.008 x$ & 2.902 n.s. \\
\hline Pupa & 215.561 (411.677) & $174.790(310.807)$ & $321.136(684.715)$ & $y=1.409+0.007 x$ & 0.741 n.s. \\
\hline
\end{tabular}

Table 1. Larval and pupal toxicity of sardine fish scales extract against Anopheles stephensi. No mortality was observed in the control. $\mathrm{LC}_{50}$ : lethal concentration was killing half of the treated organisms, $\mathrm{LC}_{90}$ : lethal concentration was killing $90 \%$ of the treated organisms, $\chi^{2}$ : Value of the chi-square, d.f.: degree of freedom, n.s.: non-significant $(\alpha=0.05)$.

\section{Materials and methods}

We confirm that all experimental protocols were approved by Institutional Animal Ethical Committee, Bharathiar University, Coimbatore, India.

Fish scale extraction procedure. Fish scale materials (Sardinella longiceps) were procured from the fish market, Ukkadam, Coimbatore, India. Fish scales were transferred to the Department of Zoology, Bharathiar University, were washed thoroughly for discarded abdicable wreckages, air-dried, and stored at $-60{ }^{\circ} \mathrm{C}$ while waiting for the next process for no more than 30 days; $\mathrm{AgNO}_{3}$ (silver nitrate $\geq 99.0 \%$ pure- $\leq 0.01 \%$ not $\mathrm{HCl}$ ), SOD, CAT, and LPO enzyme analytical kits and other chemicals were purchased from Sigma Chemicals in the USA.

Bio-synthesis and characterization of fish scale bio-fabricated silver nanoparticles (SFS-AgNPs). For the synthesis of bio-fabricated fish scale silver nanoparticles, we adopted the procedure of Murugan et al. ${ }^{19}$ which was previously described and slightly modified by Muthumari et al. ${ }^{32}$ and Dinesh et al..$^{33}$. Initially, the Sardine Fish Scale extract was made by adding $10 \mathrm{~g}$ of SFS-grains to $100 \mathrm{~mL}$ double distilled water which was then stewed at $60{ }^{\circ} \mathrm{C}$ for $20 \mathrm{~min}$ in the filtered extract used to prepare the SFS-AgNPs. The filtered SFS aqueous extract of $10 \mathrm{~mL}$ with different concentrations $(10 \%, 20 \%, 30 \%$ and $40 \%)$ was added separately to $10 \mathrm{~mL}$ of $1 \mathrm{mM} \mathrm{AgNO}$ aqueous solution and boiled at $70{ }^{\circ} \mathrm{C}$ for $10 \mathrm{~min}$ followed by incubation at room temperature for cooling the solution ${ }^{19}$. After $24 \mathrm{~h}$ the solution of dark brown sediments indicated the formation and presence of the AgNPs. Then physiochemical characterizations were done viz., UV-vis, SEM, EDX, FTIR and XRD analyses $^{34}$. SFS-AgNPs were authenticated by UV-vis, followed by SEM, EDX, FT-IR and XRD. UV-vis spectrophotometry enables the user to illustrate the shape and size of nanofabricated materials in water solution ${ }^{35}$.

Mosquitocidal properties of SFS-AgNPs on the malarial vector A. stephensi L.. The eggs and young larval and pupal mosquitoes were maintained and cultured and pathogen-free colonies were maintained at laboratory conditions $\left(27 \pm 2{ }^{\circ} \mathrm{C}, 75-85 \%\right.$ R.H. and $14 \mathrm{~h}: 10 \mathrm{~h}$ (L:D) photoperiod) following Subramaniam and Murugan ${ }^{36}$ and Subramaniam et al. ${ }^{37,38}$. We have followed the procedure by Murugan et al. ${ }^{10,39,40}$ where five replications were made. In each replicate, there were twenty-five larvae/pupae in the two hundred fifty millilitre of double distilled water including the required concentration of sardine fish scale extract (ppm) and SFS-AgNPs (ppm), respectively. Ovicidal efficiency was elaborated using methods by Mullai and Jebanesan ${ }^{41}$ and Panneerselvam and Murugan ${ }^{42}$. Hundred eggs were used for each replicate and five replications were made at different concentrations of SFS extract (50,75,100, 125 and $150 \mathrm{ppm})$ and SFS-AgNPs (10, 20, 30, 40 and $50 \mathrm{ppm})$. After $98 \mathrm{~h}$ post-treatment, egg mortality (no hatching and closed opercula) was calculated following Kovendan et al. ${ }^{43}$.

Predatory potential of G. affinis. G. affinis was maintained in the laboratory in a definite size of the fish tank and cultured fishes were used to test the predatory potential of mosquitofish. Different larval stages (I-IV) of A. stephensi were used for a predatory bioassay by Murugan et al. ${ }^{11,44}$ and Subramaniam et al. ${ }^{45}$. The feeding potential of the fishes was recorded with the decrease in doses for I-IV larvae of A. stephensi i.e. 1/3 of the LC $_{50}$ values of SFS extract (Table 1) and SFS-AgNPs (Table 2). Experiments were replicated five times and larvae were replaced daily and the experiments were monitored periodically (predatory/prey potential) the predatory efficiency was calculated by using formula originally defined by Murugan et al. ${ }^{19,34}$ and Subramaniam et al. ${ }^{46,47}$.

Collection and preparation of samples for enzyme assays. At the completion of each experimental period (1,2,4,8,16 and 28 days) fishes from control, Sardine fish scale extract and sardine fish scale silver nanoparticles were used for treatments (treatment I, II and III) at desired concentrations $(2,4,6,8$ and $10 \mathrm{ppm})$ respectively. Blood samples of organs (gills) were collected and stored at cold conditions. The tissues were used to evaluate enzymological parameters (LPO, SOD and CAT). Lipid peroxidation (LPO) was investigated following the methods described and modified by Gupta and Verma ${ }^{48}$. Chemical concentrations were estimated by the procedure of Chen et al. ${ }^{49}$. CAT activities were studied after Bao et al. ${ }^{50}$. Enzyme activation was estimated from the gill region of $G$. affinis after the treatment of fish scale biofabricated silver nanoparticles at different concentrations viz. 2, 4, 6, 8, 10 ppm concentration after different periods (i.e. 1, 2, 4, 8, 16 days respectively). 


\begin{tabular}{|l|l|l|l|l|l|}
\hline & & \multicolumn{2}{|l|}{$\mathbf{9 5 \%}$ confidence limit $\mathbf{L C}_{\mathbf{5 0}}\left(\mathbf{L C}_{\mathbf{9 0}}\right)$} & & \\
\cline { 3 - 4 } Larval instars & $\mathbf{L C}_{\mathbf{5 0}}\left(\mathbf{L} \mathbf{L C}_{\mathbf{9 0}}\right)$ & Lower & Upper & Regression equation & $\chi^{2}($ d.f. $=\mathbf{4})$ \\
\hline Larva I & $13.261(25.149)$ & $11.607(23.483)$ & $14.587(27.406)$ & $y=1.430+0.108 x$ & 0.247 n.s. \\
\hline Larva II & $16.227(28.533)$ & $14.857(26.660)$ & $17.429(31.080)$ & $y=1.690+0.104 x$ & 1.821 n.s. \\
\hline Larva III & $19.300(34.083)$ & $17.889(31.399)$ & $20.664(37.964)$ & $y=1.673+0.087 x$ & 1.954 n.s. \\
\hline Larva IV & $22.855(38.269)$ & $21.430(34.960)$ & $24.478(43.195)$ & $y=1.900+0.083 x$ & 2.437 n.s. \\
\hline Pupa & $32.182(56.822)$ & $28.742(47.631)$ & $38.427(75.093)$ & $y=1.674+0.052 x$ & $0.243 n . s$. \\
\hline
\end{tabular}

Table 2. Larval and pupal toxicity of AgNP synthesized from sardine fish scales against Anopheles stephensi. No mortality was observed in the control. $\mathrm{LC}_{50}$ : lethal concentration was killing half of the treated organisms, $\mathrm{LC}_{90}$ : lethal concentration was killing $90 \%$ of the treated organisms, $\chi^{2}$ : Value of the chi-square, $d$.f.: degree of freedom, n.s.: non-significant ( $\alpha=0.05)$.

The following enzymes, SOD, CAT and LPO were estimated in the gill region after the exposure of nanoparticles at different dose levels.

Data analysis. Lethal concentrations $\left(\mathrm{LC}_{50}\right.$ and $\left.\mathrm{LC}_{90}\right)$ were determined by probit analysis using mortality data ${ }^{51}$. The SPSS statistical package 16.0 version was used for all sample analysis calculations. All data were subjected to Analysis of variance. The means were separated using Duncan's multiple range test modified by Alder and Rossler ${ }^{52}$. Antioxidant enzyme studies SOD and calculated data were shown as means \pm SE, percentage changes were compared by the means of treated data against their controls. Data were considered significant at $(\mathrm{P}<0.01)$ and $(\mathrm{P}<0.05)$ levels.

We wish to confirm that all methods were carried out in accordance with relevant guidelines and regulations of Bharathiar University, India and for the manuscript entitled "Efficacy of bio-fabricated Sardine fish scale silver nanoparticles against malarial vector and their effect on antioxidant enzymes of mosquito fish, Gambusia affinis" which was submitted to Scientific Reports.

We are confirming that the study was carried out in compliance with the ARRIVE guidelines for the experimentations and further experimental protocol framed by the of Bharathiar University, India and for the manuscript entitled "Efficacy of bio-fabricated Sardine fish scales silver nanoparticles against malarial vector and their effect on antioxidant enzymes of mosquito fish, Gambusia affinis", which was submitted to Scientific Reports.

\section{Results and discussion}

Physicochemical characterization of nanoparticles by instrumentation techniques. Nanoparticles mediated with the aid of nanobiotechnology have provided a series of purposes viz., electronics, physics, drug delivery, stem cell therapy ${ }^{16}$. Nanostructured materials and its possessions must be examined in advanced practice. Regularly to designate the physicochemical representation of the unknown NPs, several corresponding techniques should promptly be employed (i.e. SEM, EDAX, FT-IR spectroscopy and X-ray diffraction studies) s.53 $^{6,5}$ as we did in the present study.

The reaction time of fish scale extract was visualized in the UV-visualization spectrum and provided in Fig. 2. The color intensity of the SFS extract incubated with $\mathrm{AgNO}_{3}$ solution at the start of the treatment and after $120 \mathrm{~min}$ of reaction is providing a peak at $460 \mathrm{~nm}$ (Fig. 2). Similarly, biofabrication of AgNPs was determined via a chromatic indicator represented by color change of the reaction substrate, from light green to brown which showed the biotransformation of $\mathrm{Ag}^{+}$ion to $\mathrm{Ag}^{054,55}$. The UV-vis spectra of fish scale extracts as a function of reaction time provided a strong resonance at about $410 \mathrm{~nm}$ which increased in intensity with time. The physically powerful Plasmon resonance centering at $400 \mathrm{~nm}$ increased in strength with time. This is explained with the excitation of longitudinal Plasmon vibrations of AgNPs in solution ${ }^{56}$.

Scanning electron microscope (SEM) was used to characterize the morphology of the AgNPs and to observe the dissimilarities in size, capability for accumulation, and stability of experimental conditions ${ }^{57}$. The physical structure of AgNps was visualized by adopting the SEM analysis which procured hexagonal nanostructures as presented in Fig. 3. Santhosh Kumar et al. ${ }^{58}$ demonstrated by SEM that the morphologies of Ag-Nps were unique and uniform in size from 25 to $80 \mathrm{~nm}$. Our results agreed with Murugan et al. ${ }^{14}$ that the visual part of morphology of chitosan-fabricated AgNP was studied by FE-SEM and showed spherically-shaped particles ranging from 30 to $50 \mathrm{~nm}$.

EDX spectra provided quantitative evidence and the occurrence of elements involved in the materialization of SFS-AgNPs synthesized at $25^{\circ} \mathrm{C}$ and $80^{\circ} \mathrm{C}$ (Fig. 4). The silver atoms in the SFS-AgNPs and those from oxygen, silver and chloride provided strong signals. Our results agree with Murugan et al. ${ }^{19}$ who showed that metallic silver could be confirmed by strong silver signals. The results of Energy-dispersive X-ray (EDX) spectra provided evidence from Centroceras calvulatum extract and Sonneratia alba synthesized AgNPs, respectively ${ }^{10,21}$.

The structure and crystal lattice of the SFS-AgNPs (Sardine fish scale synthesized silver nanoparticles-see Fig. 5) are categorized and authenticated by employing X-ray powder diffraction (XRD) pattern of SFS-AgNPsps. The Braggs reflections $\left(111,200,220\right.$ and 311 ) were noticed in the XRD pattern at 2 theta $28.20^{\circ}, 32.45^{\circ}, 46.50^{\circ}$ and $58.60^{\circ}$ results, corresponding to the face centered cubic structure, advocating that crystalline in nature and bioorganic junctures occur on the surface of the SFS-AgNPs. These data are in concurrence with earlier investigations. Anal and $\mathrm{Kama}^{59}$ reported about the biosynthesis of silver nanomaterials by employing fish processing waste. A XRD study indicated the occurrence of broad peaks of nanoparticles that were of very small size and 


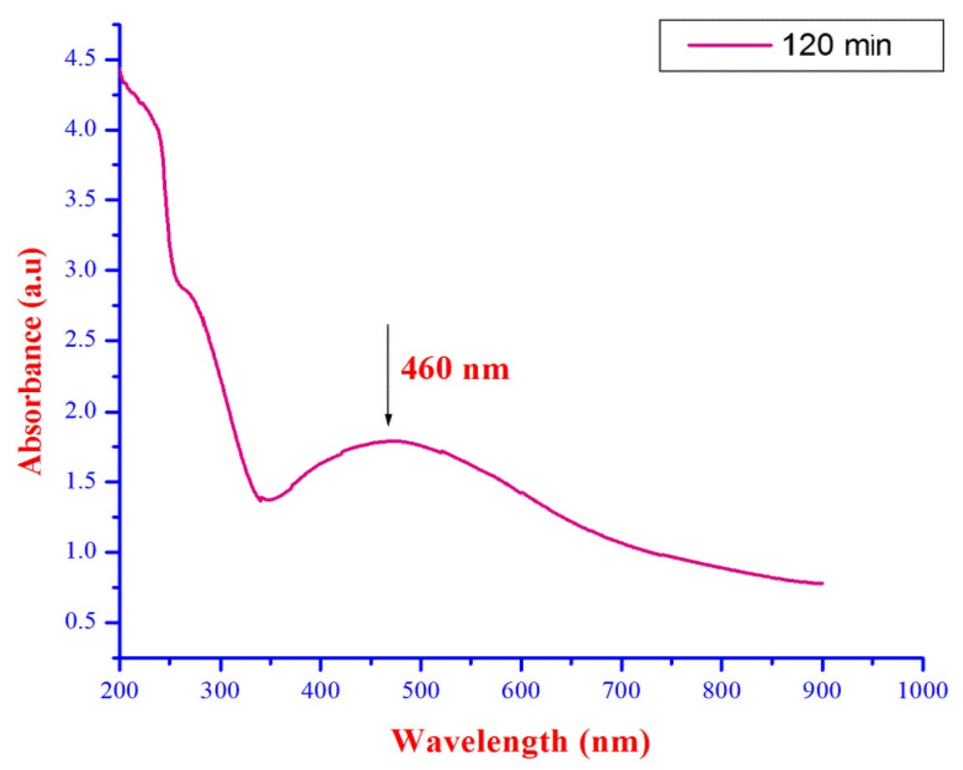

Figure 2. UV-vis spectra of the sardine fish scales fabricated AgNPs at 120 mins.

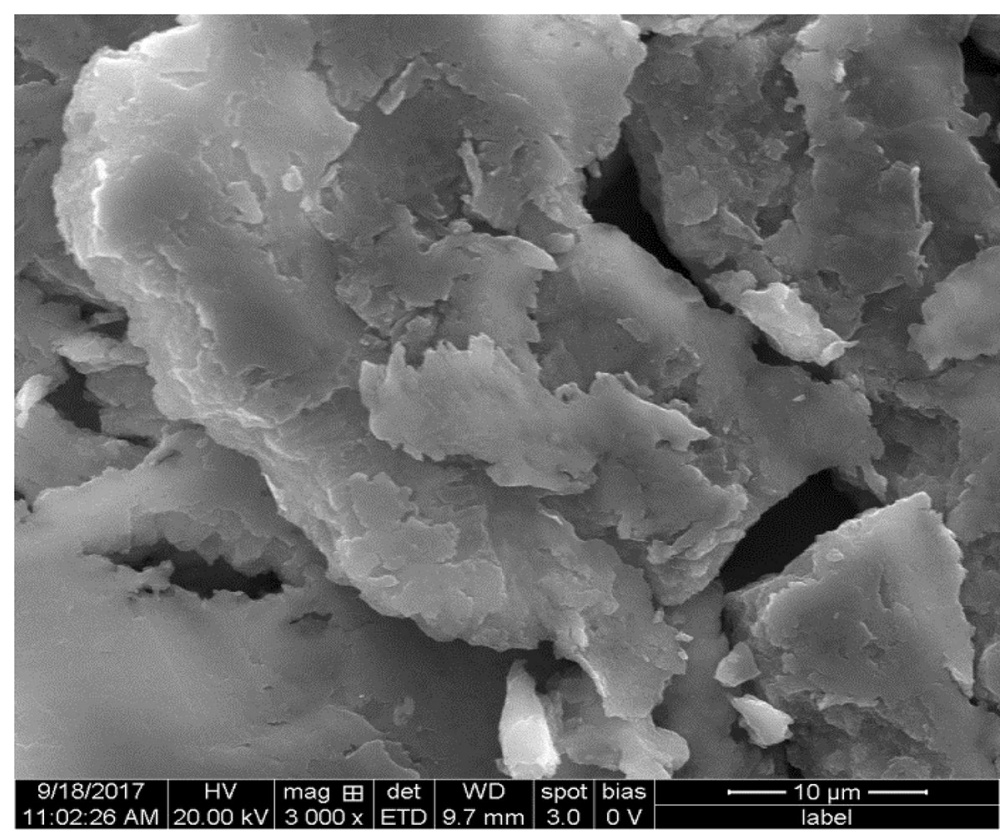

Figure 3. Scanning electron micrograph (SEM) of the sardine fish scales fabricated silver nanoparticles.

confirmed their semi-crystalline nature. Parthiban et al. ${ }^{60}$, confirmed the crystalline nature and showed that the XRD pattern intensities of silver nanoparticles from Annona reticulata had three dispersion peaks with 2 theta values, at $37.56^{\circ}, 43.25^{\circ}$ and $64.10^{\circ}(111,200$ and 220$)$ respectively ${ }^{40,61}$.

Fourier transformed infrared spectroscopy (FTIR) is another technique to determine physiochemical parameters and elucidate the structure of nanomaterials, based on the electromagnetic wavelength within the midinfrared region (4000-400 $\left.\mathrm{cm}^{-1}\right)^{62}$. The FTIR analysis represents a non-invasive, value added, economical and simple method to classify the function of biological elements in the contraction of silver nitrate to silver ${ }^{63}$. FTIR spectrum analysis could be applied to confirm the interaction among the presence of amine groups in the combined nanostructures of sardine fish scale extract and silver nitrate. Figure 6 shows spectral maxima that reveal carbonyl groups such as from polyphenols such as $\mathrm{N}-\mathrm{O}$ stretching (nitroxide compound), $\mathrm{S}=\mathrm{O}$ stretching (sulfoxide), $\mathrm{C}=\mathrm{C}$ stretching (alkene), $\mathrm{C}=\mathrm{O}$ stretching (carboxylic), $\mathrm{C}-\mathrm{H}$ stretching (alkene), $\mathrm{N}-\mathrm{H}$ stretching (secondary amine), respectively. Altogether the data of the present study indicate that particles secured by Ag Nanomaterials had free and bound alkane and amine groups ${ }^{64}$. 


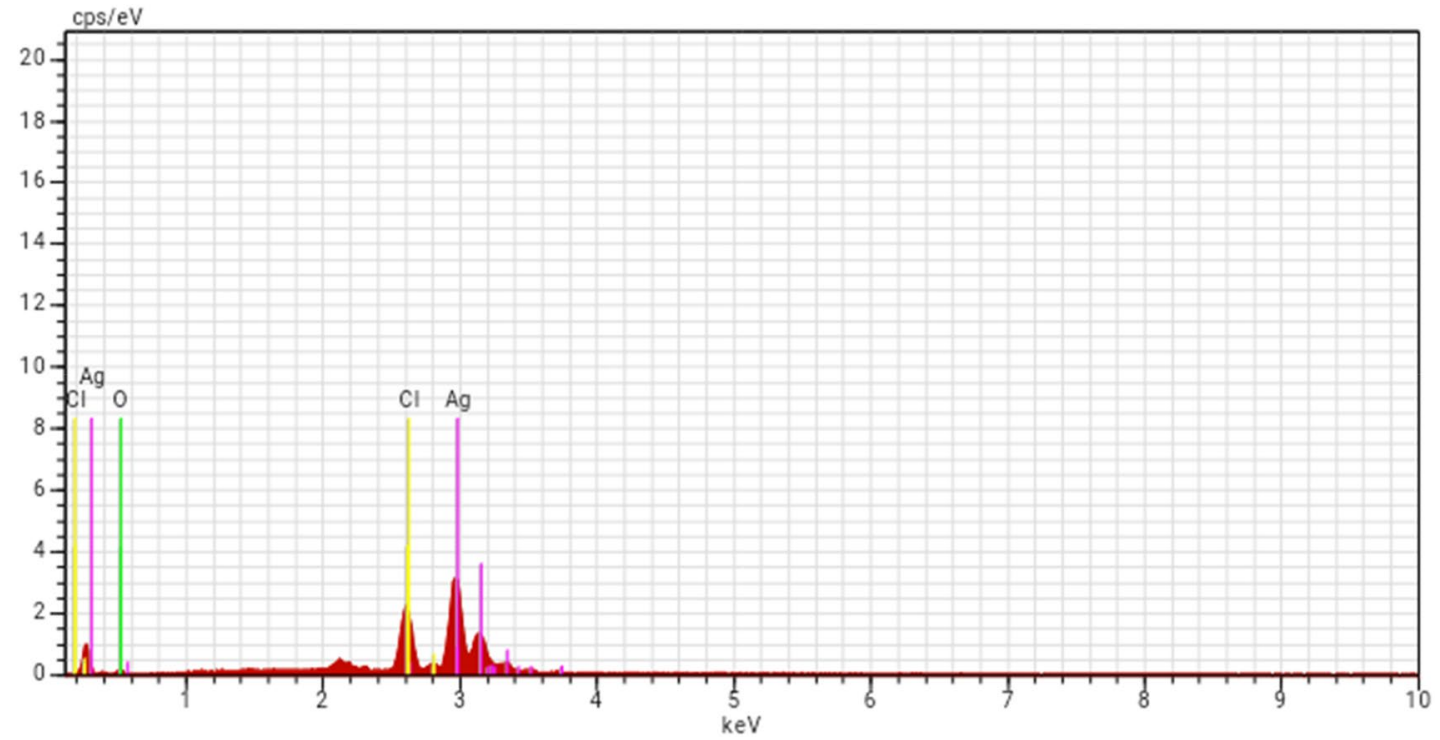

Figure 4. Energy-dispersive X-ray spectrum (EDX) of AgNPs fabricated sardine fish scale extract.

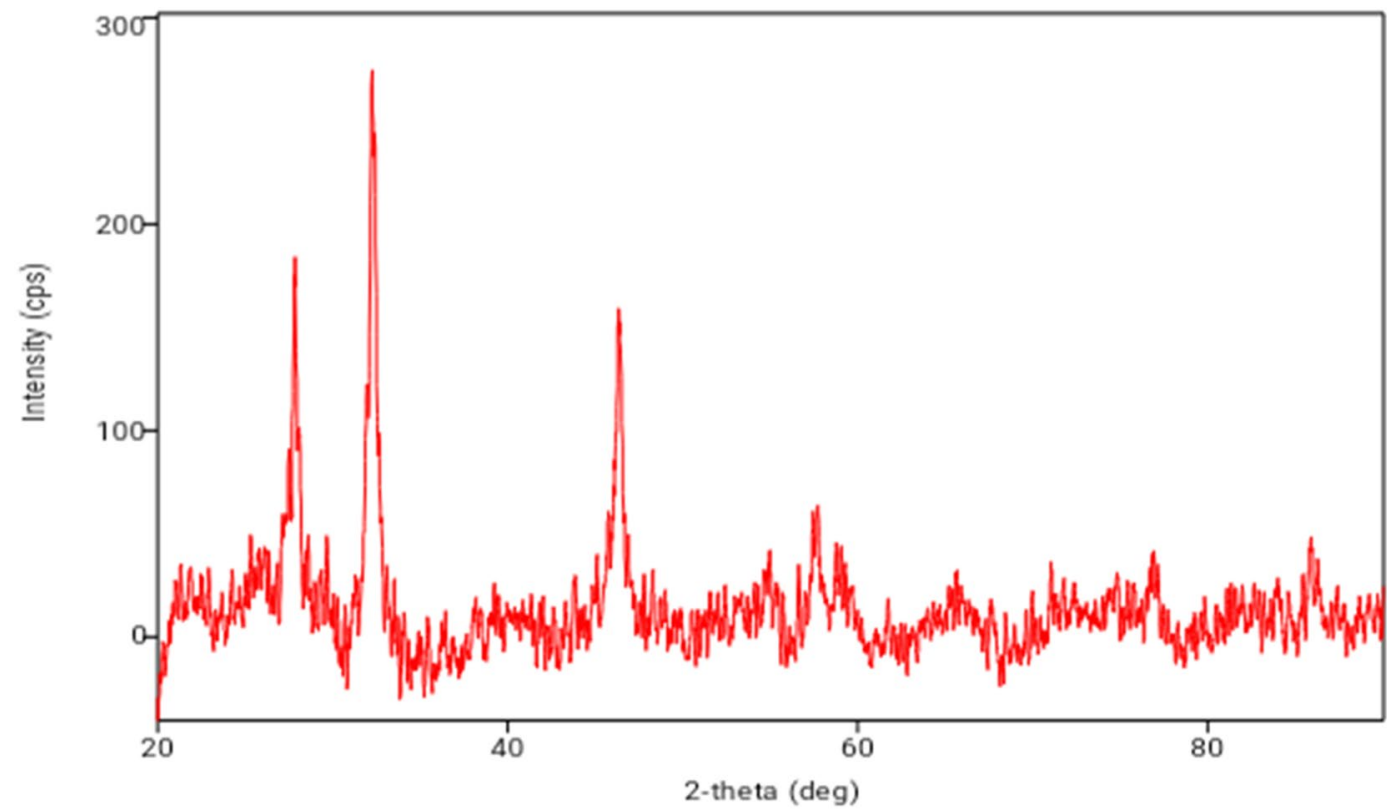

Figure 5. XRD pattern of the sardine fish scales fabricated silver nanoparticles.

Similarly, many researchers have studied that biofabricated nanoparticles are possessing different functional groups, including alkene and alkane ${ }^{65,66}$, methylene ${ }^{67}$, aromatic amine ${ }^{68}$, and carboxylic acid ${ }^{33}$, carboxyl groups or/in amide groups ${ }^{67}$ were revealed in earlier studies as reducing agents in the biofabrication of AgNPs.

Nanoparticles as mosquito larvicides. Sardine fish scale extract and its biosynthesized silver nanoparticles with various concentrations expressed their toxicity against young instars and pupal populations of the malarial vector. However, the toxic effect was significantly higher in biosynthesized silver nanoparticles and these results are shown in Tables 1 and 2. For example, in the case of fish scale extract treatment of the fourth instar larvae, its $\mathrm{LC}_{50}$ was $170.38 \mathrm{ppm}$ and for fish scale biosynthesized silver nanoparticles the $\mathrm{LC}_{50}$ was $22.85 \mathrm{ppm}$, respectively. Moreover, most of the biogenic nanostructures are spherical in shape ${ }^{69}$ with only some exceptionally being of oval shape $\mathrm{e}^{70}$. Similar to earlier studies, the fish scale nanoparticles in the present study are also spherical and provided greater larval and pupal toxicity to mosquitoes ${ }^{40}$.

Nanoparticles as mosquito ovicides. Sardine fish scale extract and sardine fish scale biosynthesized nanoparticles greatly affected the hatchability of eggs of mosquito vectors (Table 3). There was no hatching $(\mathrm{NH})$ occurring at $150 \mathrm{ppm}$ sardine fish scale extract whereas the sardine fish scale biosynthesized nanoparticles pro- 


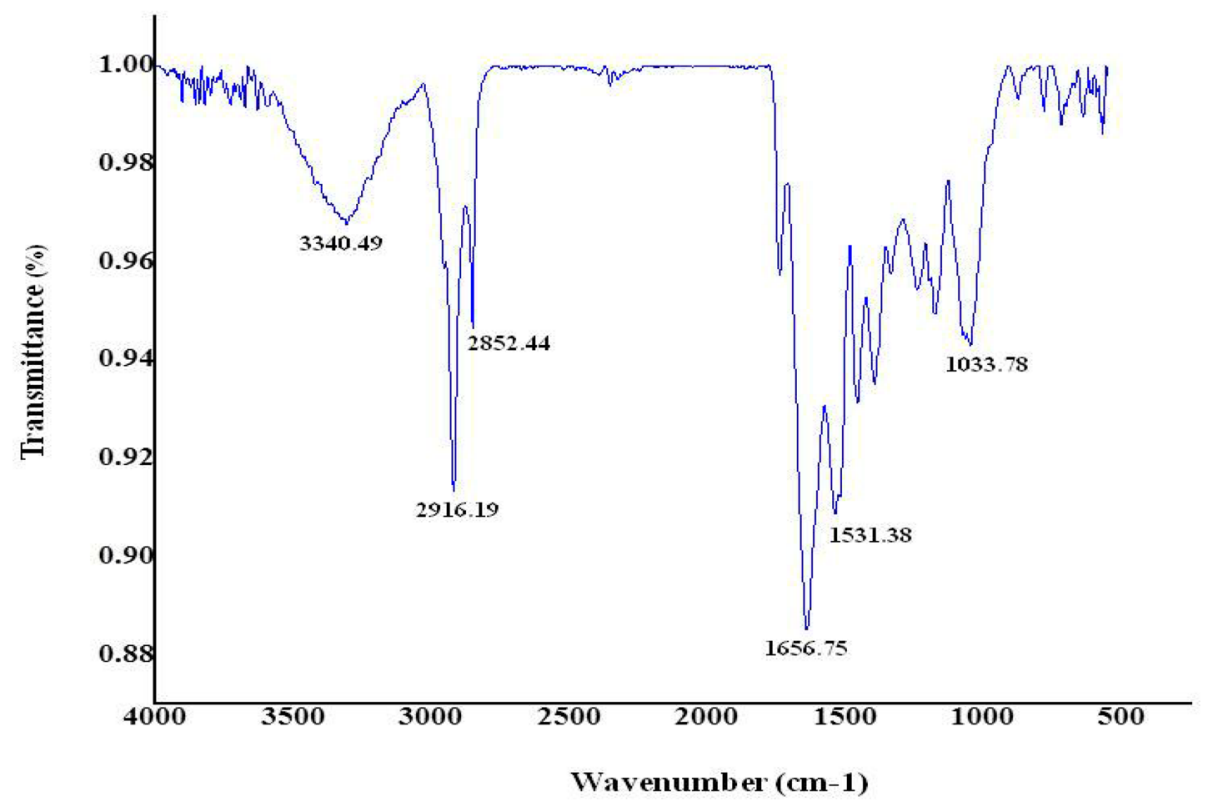

Figure 6. Fourier transform infrared (FTIR) spectrum of AgNPs fabricated sardine fish scale extract.

\begin{tabular}{|c|c|c|c|c|c|c|c|c|}
\hline \multirow[b]{3}{*}{ Treatment } & \multicolumn{8}{|c|}{ Egg hatchability (\%) } \\
\hline & \multicolumn{8}{|c|}{\begin{tabular}{|l|} 
Concentration (ppm) \\
\end{tabular}} \\
\hline & Control & $50 \mathrm{ppm}$ & 75 ppm & 100 ppm & 125 ppm & $150 \mathrm{ppm}$ & $\begin{array}{l}\text { Regression } \\
\text { equation }\end{array}$ & $\chi^{2}($ d.f. $=4)$ \\
\hline \multirow[t]{2}{*}{$\begin{array}{l}\text { Sardine fish scales } \\
\text { extract }\end{array}$} & $80.4 \pm 1.34^{\mathrm{a}}$ & $63.8 \pm 1.48^{\mathrm{b}}$ & $52.0 \pm 1.87^{c}$ & $33.4 \pm 1.14^{\mathrm{d}}$ & $25.2 \pm 0.83^{\mathrm{e}}$ & $\mathrm{NH}$ & $y=1.469+0.020 x$ & 14.87 \\
\hline & Control & $10 \mathrm{ppm}$ & $20 \mathrm{ppm}$ & $30 \mathrm{ppm}$ & $40 \mathrm{ppm}$ & $50 \mathrm{ppm}$ & & \\
\hline $\begin{array}{l}\text { Sardine fish scale } \\
\text { extract-AgNPs }\end{array}$ & $92.4 \pm 0.54^{\mathrm{a}}$ & $53.2 \pm 1.09^{b}$ & $41.8 \pm 1.30^{c}$ & $23.4 \pm 0.89^{\mathrm{d}}$ & $\mathrm{NH}$ & $\mathrm{NH}$ & $y=0.940+0.066 x$ & 15.50 \\
\hline
\end{tabular}

Table 3. Ovicidal activity of sardine fish scales extract against the malarial vector Anopheles stephensi. NH-No hatchability (100\% mortality). Means followed by the same letter are not significantly different $(\mathrm{P}<0.05)$.

vided no hatchability $(\mathrm{NH})$, even at the lowest dose group of $40 \mathrm{ppm}$. Madhiyazhagan et al. ${ }^{71}$ conducted experiments against malarial, filarial, and dengue vector and Sargassum muticum-fabricated silver nanostructures with a single dose $(30 \mu \mathrm{g} / \mathrm{mL})$ expressing significant ovicidal activities. Furthermore, Rajaganesh et al. ${ }^{72}$ found that $25 \mu \mathrm{g} / \mathrm{mL}$ administration led to $100 \%$ inhibition of hatchability by the exposure to fern (Dicranopteris linearis)fabricated nanostructures.

Predatory efficiency of $G$. affinis combined with SFS extract and SFS-AgNPs against $A$. stephensi. Predatory fish showed a high predation activity against malarial vectors and the first instar larvae were the most preferred food for the mosquito fish, G. affinis. In our predation experiments, predatory efficiency was $79.70 \%$ (first instar), $70.55 \%$ (second instar), $62.75 \%$ (third instar) and $46.30 \%$ (fourth instar), respectively (Table 4). Notably, predatory efficacy of G. affinis after application of silver nanoparticles at their elevated dose level reached $94.15 \%, 84.30 \%, 71.05 \%$ and $56.50 \%$, from first to fourth instar larvae, respectively (Table 4 ).

Effect of nanoparticles against non-target aquatic organisms. Silver nanoparticles were tested before for their acute toxicity ${ }^{55}$. Most of the biosynthesized silver nanoparticles did not show any toxicity against any aquatic organism ${ }^{73}$. For instance, plant synthesized silver nanoparticles did not show any toxic impact compared to fabricated nanomaterials to the predatory fish Poecilia reticulata after an exposure for 48 h. Earlier, Murugan et al. ${ }^{21}$ reported that a treatment with $S$. alba synthesized AgNP increased neither the consumption of predatory fish nor of guppy fish (Poecilia reticulata) for mosquito larvae.

Antioxidant enzyme response to nanoparticle contaminated environments for non-target mosquito fish. After exposure of fish to different doses of fish scale biofabricated silver nanoparticles there was a changing profile of enzyme activities in the gill region of the fish. Sodium dismutase (SOD) is a oxyradical scavenger and is mainly involved in the catalytic activity and liable for dismutation of exceedingly abundant superoxide radicals. A significant increase in the activity of SOD was noted (Fig. 7). This may be due to the 


\begin{tabular}{|l|l|l|l|l|l|}
\hline Treatment & Target & Day light time (n) & Night time (n) & Total predation nos & Percentage of predation \\
\hline \multirow{4}{*}{ Standard conditions } & I instar & $174.0 \pm 1.22^{\mathrm{d}}$ & $144.8 \pm 2.68^{\mathrm{cd}}$ & 318.8 & $79.7^{\mathrm{d}}$ \\
\cline { 2 - 6 } & II instar & $158.8 \pm 0.83^{\mathrm{c}}$ & $123.4 \pm 1.51^{\mathrm{c}}$ & 282.2 & $70.55^{\mathrm{c}}$ \\
\cline { 2 - 6 } & III instar & $138.6 \pm 0.54^{\mathrm{b}}$ & $112.4 \pm 1.81^{\mathrm{b}}$ & 251.0 & $62.75^{\mathrm{b}}$ \\
\cline { 2 - 6 } & IV instar & $097.2 \pm 2.04^{\mathrm{a}}$ & $088.0 \pm 1.22^{\mathrm{a}}$ & 185.2 & $46.3^{\mathrm{a}}$ \\
\hline \multirow{3}{*}{ Post-treatment with AgNPs } & I instar & $193.6 \pm 1.14^{\mathrm{d}}$ & $183.0 \pm 1.22$ & 376.6 & $94.15^{\mathrm{d}}$ \\
\cline { 2 - 6 } & II instar & $172.6 \pm 0.89^{\mathrm{bc}}$ & $164.6 \pm 1.51^{\mathrm{c}}$ & 337.2 & $84.3^{\mathrm{c}}$ \\
\cline { 2 - 6 } & III instar & $155.8 \pm 1.64^{\mathrm{b}}$ & $128.4 \pm 0.89^{\mathrm{b}}$ & 284.2 & $71.05^{\mathrm{b}}$ \\
\cline { 2 - 6 } & IV instar & $122.6 \pm 1.14^{\mathrm{a}}$ & $103.4 \pm 1.51^{\mathrm{a}}$ & 226.0 & $56.5^{\mathrm{a}}$ \\
\hline
\end{tabular}

Table 4. Predatory efficiency on mosquito A. stephensi by the teleost fish Gambusia affinis. Predation rates are represented by means \pm SD of four replicates ( 1 fish vs 200 mosquitoes per replicate). Control was clean water without predators within each column, means followed by the same letter are not. Significantly different $(\mathrm{P}<0.05)$.

\section{SOD levels in Gills}

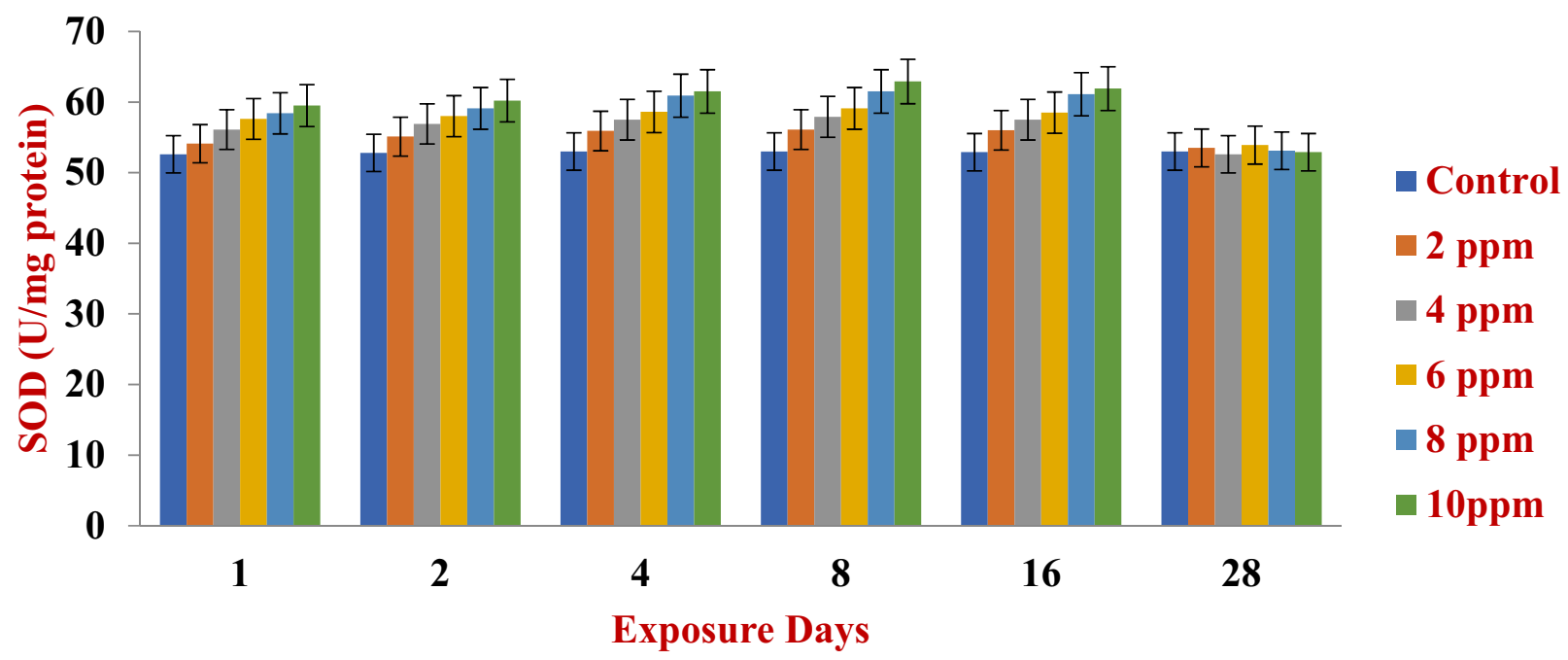

Figure 7. SOD enzymes in the gill region after the exposure (1-28 days) to AgNPs at different doses.

synthesis of newer enzymes in the body system or enrichment of already existing enzymes loaded in the tissues at different concentrations. Interestingly, the level initially increased during 1, 2, 4 and 8 days and its level has been resumed very near to the uncontaminated biofabricated nanoparticles of fish scales. A similar study was conducted after the treatment of $\mathrm{Cu}$ nanoparticles at $25.6 \mu \mathrm{g} \mathrm{L} \mathrm{L}^{-1}$ after a $24 \mathrm{~h}$ treatment of gills of the mytilid clams B. azoricus $^{74}$ and M. galloprovincialis after exposure to $5-25 \mu \mathrm{g} \mathrm{L}^{-1} \mathrm{Cu}$ after 7 day treatment ${ }^{75}$.

Catalase (CAT) activation provides another stress/antioxidant system of animals. This enzyme converts the free radicals $\mathrm{H}_{2} \mathrm{O}_{2}$ to $\mathrm{H}_{2} \mathrm{O}$ and $\mathrm{O}_{2}$ in the animal defense system. In our experiment after exposure to fish scale fabricated nanoparticles at 2, 4, 6, 8 and $10 \mathrm{ppm}$, the antioxidant enzyme (CAT) had slightly increased its activities up to day 1, 2 and 4 where it showed considerably elevated activities (Fig. 8). Yilmaz et al. ${ }^{76}$ reported peroxisome distributions in the gill region and its functional role on molecular $\mathrm{H}_{2} \mathrm{O}_{2}$ which is metabolized to molecular $\mathrm{O}_{2}$ and $\mathrm{H}_{2} \mathrm{O}$.

LPO is yet another very important indicator of oxidative enzymes in the cellular metabolism and it is the end product or outcome of oxidative deterioration of membrane lipids. LPO serves as a marker or oxidative enzyme and it has been extensively used as a biomarker for cellular activities ${ }^{77}$. Normally this enzyme (LPO) is evaluated/ estimated by measuring the concentration of malondialdehyde (MDA) (Fig. 9). The higher activities and overaccumulation of the enzyme malondialdehyde not only damages cells but also triggers the process of apoptosis ${ }^{78}$. In the current study there was no change in the gills after nanoparticle exposure. However, a significant elevation of this enzyme was noted after 1, 2, 4 and 8 days.

\section{Conclusion}

In conclusion, Sardine fish scale fabricated nanomaterials are hydrophilic, can uniformly disperse in aqueous media, have moderate toxic effects and provide mosquitocidal properties against the malarial vector Anopheles stephensi. The biosynthesized silver nanoparticles of this study are easy to prepare with high stability and provide pronounced toxic effects on target mosquito vectors. At the same time the nanoparticles used here enhance 


\section{CAT level in Gills}

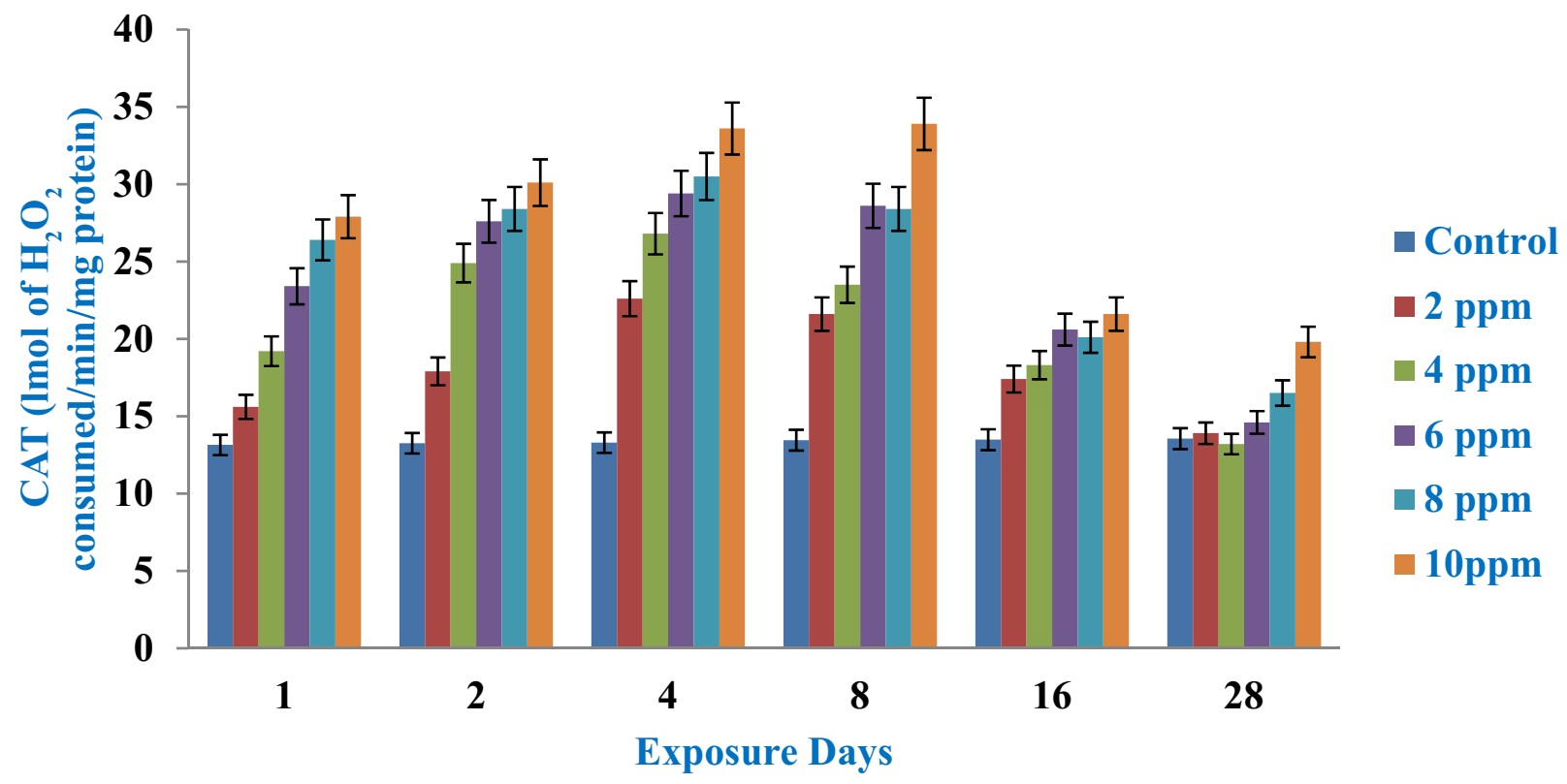

Figure 8. CAT enzymes in the gill region after the exposure (1-28 days) to AgNPs at different doses.

\section{LPO levels in Gills}

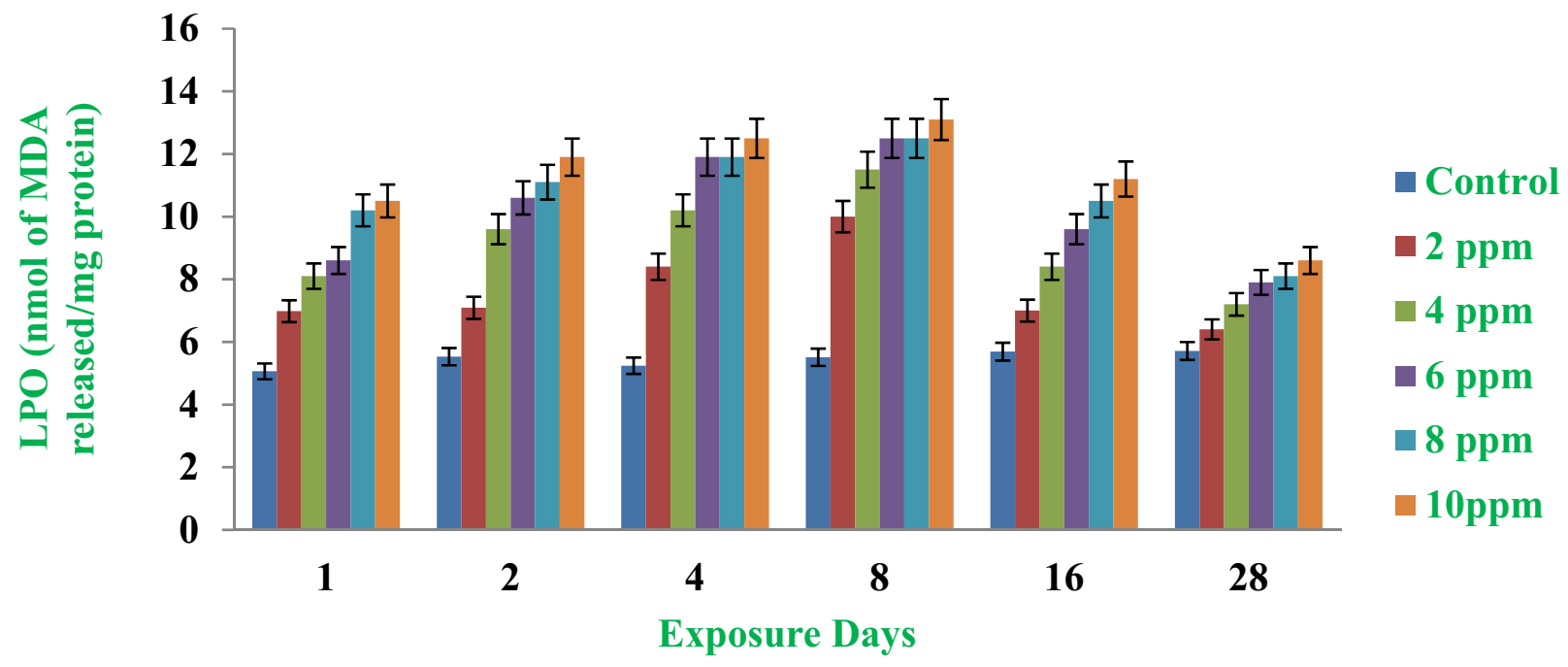

Figure 9. LPO enzymes in the gill region after the exposure (1-28 days) to AgNPs at different doses.

the feeding activities of mosquito fish in an environment that is nanoparticle contaminated to feed on target mosquito larvae. The present paper also revealed that physiological stress extended to changed enzymological activity levels of the mosquito fish G. affinis in a nanoparticle treated environment.

Received: 19 April 2021; Accepted: 20 August 2021

Published online: 01 October 2021

\section{References}

1. Menzies, A. K. et al. Body temperature, heart rate, and activity patterns of two boreal homeotherms in winter: Homeostasis, allostasis, and ecological coexistence. Funct. Ecol. 34, 2292-2301 (2020).

2. World Health Organization. Global vector control response 2017-2030. Licence: CC BY-NC-SA 3.0 IGO (2017).

3. Jia, Q., Dahms, H. U. \& Wang, L. Detection of metallothionein proteins by enzyme-linked immunosorbent assay (ELISA). Curr. Pharm. Biotechnol. 21, 544-554 (2020). 
4. Radhika, J. \& Sathya, P. In vitro macrofilaricidal activity of traditional medicinal plants. World. J. Pharm. Pharm. Sci. 3, 1034-1042 (2014).

5. Suresh, U. et al. Suaeda maritima-based herbal coils and green nanoparticles as potential biopesticides against the dengue vector Aedes aegypti and the tobacco cutworm Spodoptera litura. Physiol. Mol. Plant. Pathol. 101, 225-235 (2018).

6. Tanur, S. M., Ahmaruzzaman, A. K. \& Sil, B. A. Biomimetic synthesis of silver nanoparticles using the fish scales of Labeo rohita and their application as catalysts for the reduction of aromatic nitro compounds. Spect. Acta. Part A Mol. Biomol. Spectros. 131, 413-423 (2014).

7. Benelli, G. F. et al. Mosquito control with green nanopesticides: Towards the One Health approach? A review of non-target effects. Environ. Sci. Pollut. Res. 25, 10184-10206 (2018).

8. Huang, H., Jia, Q. Y., Jing, W., Dahms, H. U. \& Wang, L. Screening strains for microbial biosorption technology of cadmium. Chemosphere 251, 126428 (2020).

9. Kokura, S. et al. Silver nanoparticles as a safe preservative for use in cosmetics. Nanomedicine 6, 570-574 (2010).

10. Murugan, K. et al. Fighting arboviral diseases: Low toxicity on mammalian cells, dengue growth inhibition (in vitro) and mosquitocidal activity of Centroceras clavulatum-synthesized silver nanoparticles. Parasitol. Res. 115, 651-662 (2016).

11. Murugan, K. et al. Synthesis of nanoparticles using chitosan from crab shells: Implications for control of malaria mosquito vectors and impact on non-target organisms in the aquatic environment. Ecotoxicol. Environ. Saf. 132, 318-328 (2016).

12. Sujitha, V. et al. Green-synthesized CdS nano-pesticides: Toxicity on young instars of malaria vectors and impact on enzymatic activities of the non-target mud crab Scylla serrata. Aquat. Toxicol. 188, 100-108 (2017).

13. Kalimuthu, K. et al. Predatory efficiency of the copepod Megacyclops formosanus and toxic effect of the red alga Gracilaria firmaSynthesized silver nanoparticles against the dengue vector Aedes aegypti. Hydrobiologia 785, 359-372 (2017).

14. Murugan, K. et al. Chitosan-fabricated Ag nanoparticles and larvivorous fishes: A novel route to control the coastal malaria vector Anopheles sundaicus?. Hydrobiologia 797, 335-350 (2017).

15. Dahms, H. U. New challenges by toxic threats to the environment. Environ. Toxicol. Stud. J. 2, 7 (2018).

16. Lebrato, $\mathrm{M}$. et al. Global variability in seawater Mg: $\mathrm{Ca}$ and Sr: Ca ratios in the modern ocean. PNAS 267, 115460 (2020).

17. Dambach, P. The use of aquatic predators for larval control of mosquito disease vectors: Opportunities and limitations. Biol. Control 150, 104357 (2020).

18. Cano-Rocabayera, O., Vargas-Amengual, S., Aranda, C., De Sostoa, A. \& Maceda-Veiga, A. Mosquito larvae consumption in turbid waters: The role of the type of turbidity and the larval stage in native and invasive fish. Hydrobiologia 847, 1371-1381 (2020).

19. Murugan, K. et al. Toxicity of seaweed-synthesized silver nanoparticles against the filariasis vector Culex quinquefasciatus and its impact on predation efficiency of the cyclopoid crustacean Mesocyclops longisetus. Parasitol. Res. 114, 2243-2253 (2015).

20. Kalimuthu, K. et al. Control of dengue and Zika virus vector Aedes aegypti using the predatory copepod Megacyclops formosanus: Synergy with Hedychium coronarium-synthesized silver nanoparticles and related histological changes in targeted mosquitoes. Process Saf. Environ. Prot. 109, 82-96 (2017).

21. Murugan, K. et al. Mangrove helps: Sonneratia alba-synthesized silver nanoparticles magnify guppy fish predation against Aedes aegypti young instars and down-regulate the expression of envelope (E) gene in dengue virus (Serotype DEN-2). J. Clust. Sci. 28, 437-461 (2017).

22. Li, N. et al. Lead accumulation, oxidative damage and histopathological alteration in testis and accessory glands of the freshwater crab, Sinopotamon henanense, induced by acute lead exposure. Ecotoxicol. Environ. Saf. 117, 20-27 (2015).

23. Liu, J., Dahms, H. U. \& Wang, L. Mitigative effects of zinc on cadmium-induced reproductive toxicity in the male freshwater crab Sinopotamon henanense. Environ. Sci. Pollut. Res. 27, 16282-16292 (2020).

24. Hong J. F., Ouddane B., Hwang J. S. \& Dahms, H. U. In silico assessment of human health risks caused by cyanotoxins from cyanobacteria. Biocell 45(1), 65-77 (2021).

25. Valavanidis, A., Vlachogianni, T. \& Fiotakis, K. L. S. Pulmonary oxidative stress, inflammation and cancer: Respirable particulate matter, fibrous dusts and ozone as major causes of lung carcinogenesis through reactive oxygen species mechanisms. Int. J. Environ. Res. Public Health 10, 3886-3907 (2013).

26. Zhou, Y., Jing, W., Dahms, H. U., Hwang, J. S. \& Wang, L. Oxidative damage, ultrastructural alterations and gene expressions of hemocytes in the freshwater crab Sinopotamon henanense exposed to cadmium. Ecotoxicol. Environ. Saf. 138, 130-138 (2017).

27. Li, B. et al. Biogenic selenium and its hepatoprotective activity. Sci. Rep. 7, 1-11 (2017).

28. Lin, Y., Huang, J. J., Dahms, H. U., Zhen, J. J. \& Ying, X. P. Cell damage and apoptosis in the hepatopancreas of Eriocheir sinensis induced by cadmium. Aquat. Toxicol. 190, 190-198 (2017).

29. Livingstone, D. R. Contaminant stimulated reactive oxygen species production and oxidative damage in aquatic organisms. Mar. Pollut. Bull. 42, 656-666 (2001).

30. Kobeticova, K. \& Cerny, R. Ecotoxicology of building materials: A critical review of recent studies. J. Clean. Prod. 165, 500-508 (2017).

31. Grillo, R., Fraceto, L. F., Amorim, M. J., Scott-Fordsmand, J. J., Schoonjans, R. \& Chaudhry, Q. Ecotoxicological and regulatory aspects of environmental sustainability of nanopesticides. J. Hazard. Mater. 404(Part A), 124148 (2021).

32. Muthumari, K., Anand, M. \& Maruthupandy, M. Collagen extract from marine finfish scales as a potential mosquito larvicide. Protein. J. 35, 391-400 (2016).

33. Dinesh, D. et al. Mosquitocidal and antibacterial activity of green-synthesized silver nanoparticles from Aloe vera extracts: Towards an effective tool against the malaria vector Anopheles stephensi?. Parasitol. Res. 114, 1519-1529 (2015).

34. Murugan, K. et al. Cymbopogon citratus-synthesized gold nanoparticles boost the predation efficiency of copepod Mesocyclops aspericornis against malaria and dengue mosquitoes. Exp. Parasitol. 153, 129-138 (2015).

35. Mahesh Kumar, P. et al. Biosynthesis, characterization, and acute toxicity of Berberis tinctoria-fabricated silver nanoparticles against the Asian tiger mosquito, Aedes albopictus, and the mosquito predators Toxorhynchites splendens and Mesocyclops thermocyclopoides. Parasitol. Res. 115, 751-759 (2015).

36. Subramaniam, J.; Murugan, K. Evaluation of larvicidal, pupicidal, repellent, and adulticidal activity of Myristica fragrans (Family: Myristicaceae) against malarial vector Anopheles stephensi. In Proceedings of the National Conference on Insect Diversity and Systematics: Special Emphasis on Molecular Approaches 1-6 (2013).

37. Subramaniam, J., Murugan, K. \& Kovendan, K. Larvicidal and pupcidal efficacy of Momordica charantia leaf extract and bacterial insecticide, Bacillus thuringiensis against malarial vector, Anopheles stephensi Liston. (Diptera: Culicidae). J. Biopest. 5, 163 (2012).

38. Subramaniam, J., Kovendan, K., Mahesh Kumar, P., Murugan, K. \& Walton, W. Mosquito larvicidal activity of Aloe vera (Family: Liliaceae) leaf extract and Bacillus sphaericus, against Chikungunya vector, Aedes aegypti. Saudi. J. Biol. Sci. 19, 503-509 (2012).

39. Murugan, K. et al. Fabrication of nano-mosquitocides using chitosan from crab shells: Impact on nontarget organisms in the aquatic environment. Ecotoxicol. Environ. Saf. 132, 318-328 (2016).

40. Murugan, K. et al. Carbon and silver nanoparticles in the fight against the filariasis vector Culex quinquefasciatus: Genotoxicity and impact on behavioral traits of non-target aquatic organisms. Parasitol. Res. 115, 1071-1083 (2016).

41. Mullai, K. \& Jebanesan, A. Larvicidal and ovicidal activity of the leaf extract of two cucurbitaceous plants against the filarial vector, Culex quinquefasciatus Say. Ind. J. Environ. Ecoplan. 12, 611-615 (2006).

42. Panneerselvam, C. \& Murugan, K. Adulticidal, repellent, and ovicidal properties of indigenous plant extracts against the malarial vector, Anopheles species (Diptera: Culicidae). Parasitol. Res. 112, 679-692 (2013). 
43. Kovendan, K., Murugan, K., Kumar, P. M., Thiyagarajan, P. \& William, S. J. Ovicidal, repellent, adulticidal, and field evaluations of plant extract against dengue, malaria, and filarial vectors. Parasitol. Res. 112, 1205-1219 (2013).

44. Murugan, K. et al. Ecofriendly drugs from the marine environment: Spongeweed synthesized silver nanoparticles are highly effective on Plasmodium falciparum and its vector Anopheles stephensi, with little non-target effects on predatory copepods. Environ. Sci. Pollut. Res. 23, 16671-16685 (2016).

45. Subramaniam, J. et al. Eco-friendly control of malaria and arbovirus vectors using the mosquitofish Gambusia affinis and ultralow dosages of Mimusops elengi-synthesized silver nanoparticles: Towards an integrative approach?. Environ. Sci. Pollut. Res. 22, 20067-20083 (2015).

46. Subramaniam, J. et al. Multipurpose effectiveness of Couroupita guianensis-synthesized gold nanoparticles: High antiplasmodial potential, field efficacy against malaria vectors and synergy with Aplocheilus lineatus predators. Environ. Sci. Pollut. Res. 23, 7543-7558 (2016)

47. Subramaniam, J. et al. Do Chenopodium ambrosioides-synthesized silver nanoparticles impact Oryzias melastigma predation against Aedes albopictus larvae?. J. Clust. Sci. 28, 413-436 (2017).

48. Gupta, P. \& Verma, S. K. Evaluation of genotoxicity induced by herbicide pendimethalin in fresh water fish Clarias batrachus (Linn.) and possible role of oxidative stress in induced DNA damage. Drug Chem. Toxicol. 1-10 (2020).

49. Chen, C. Y., Lu, T. H., Yang, Y. F. \& Liao, C. M. Toxicokinetic/toxicodynamic-based risk assessment of freshwater fish health posed by microplastics at environmentally relevant concentrations. Sci. Total. Environ. 756, 144013 (2020).

50. Bao, S., Tang, W. \& Fang, T. Sex-dependent and organ-specific toxicity of silver nanoparticles in livers and intestines of adult zebrafish. Chemosphere 249, 126172 (2020).

51. Finney, D. J. Probit Analysis 68-72 (Cambridge University Press, 1971).

52. Alder, H. L. \& Rossler, E. B. Introduction to Probability and Statistics 6th edn, 246 (Freeman, 1977).

53. Behzadi, S. et al. Determination of nanoparticles using UV-Vis spectra. Nanoscale 7, 5134-5139 (2015).

54. Jena, J., Pradhan, N., Dash, B. P., Sukla, L. B. \& Panda, P. K. Biosynthesis and characterization of silver nanoparticles using microalga Chlorococcum humicola and its antibacterial activity. Int. J. Nanomater. Biostruct. 3, 1-8 (2013).

55. Khoshnamvand, M. et al. Toxicity of biosynthesized silver nanoparticles to aquatic organisms of different trophic levels. Chemosphere 258, 127346 (2020).

56. Sivapriyajothi, S., Kumar, P. M., Kovendan, K., Subramaniam, J. \& Murugan, K. Larvicidal and pupicidal activity of synthesized silver nanoparticles using Leucas aspera leaf extract against mosquito vectors, Aedes aegypti and Anopheles stephensi. J. Entomol. Acarol. Res. 29, 77-84 (2014).

57. Fatema, S., Shirsat, M., Farooqui, M. \& Pathan, M. A. Biosynthesis of silver nanoparticle using aqueous extract of Saraca asoca leaves, its characterization and antimicrobial activity. Int. J. Nano Dimens. 10, 163-168 (2019).

58. Santhoshkumar, T. et al. Synthesis of silver nanoparticles using Nelumbonucifera leaf extract and its larvicidal activity against malaria and filariasis vectors. Parasitol. Res. 108, 693-702 (2011).

59. Anal, K. J. \& Kamal, P. Synthesis of silver nanoparticles employing fish processing discard: An eco-amenable approach. J. Chin. Adv. Mater. Soc. 3, 179-185 (2014).

60. Parthiban, E., Manivannan, N., Ramanibai, R. \& Mathivanan, N. Green synthesis of silver-nanoparticles from Annona reticulate leaves aqueous extract and its mosquito larvicidal and anti-microbial activity on human pathogens. Biotechnol. Rep. 20, e00297 (2018).

61. Priyadarshini, K. A. et al. Biolarvicidal and pupicidal potential of silver nanoparticles synthesized using Euphorbia hirta against Anopheles stephensi Liston (Diptera: Culicidae). Parasitol. Res. 111, 997-1006 (2012).

62. Mourdikoudis, S., Pallares, R. M., Nguyen, T. K. \& Than, H. Characterization techniques for nanoparticles: Comparison and complementarity upon studying nanoparticle properties. Rev. Nanoscale. 10, 12871-12934 (2018).

63. Zhang, X. F., Liu, Z. G., Shen, W. \& Gurunathan, S. Silver nanoparticles: Synthesis, characterization, properties, applications, and therapeutic approaches. Int. J. Mol. Sci. 17, 1534 (2016).

64. Begum, R. et al. Applications of UV/Vis spectroscopy in characterization and catalytic activity of noble metal nanoparticles fabricated in responsive polymer microgels. A review. Crit. Rev. Anal. Chem. 48, 503-516 (2018).

65. Rezazadeh, N. H., Buazar, F. \& Matroodi, S. Synergistic effects of combinatorial chitosan and polyphenol biomolecules on enhanced antibacterial activity of biofunctionalized silver nanoparticles. Sci. Rep. 10, 1-13 (2020).

66. Rajeshkumar, S. \& Sandhiya, D. Biomedical applications of zinc oxide nanoparticles synthesized using eco-friendly method. In Nanoparticles and their Biomedical Applications 65-93 (2020).

67. Bankar, A., Joshi, B., Kumar, A. R. \& Zinjarde, S. Banana peel extract mediated novel route for the synthesis of silver nanoparticles. Coll. Surf. A. 368, 58-63 (2010).

68. Suganya, A., Murugan, K., Kovendan, K., Mahesh Kumar, P. \& Hwang, J. S. Green synthesis of silver nanoparticles using Murraya koenigii leaf extract against Anopheles stephensi and Aedes aegypti. Parasitol. Res. 112, 1385-1397 (2013).

69. Benelli, G. Plant-mediated biosynthesis of nanoparticles as an emerging tool against mosquitoes of medical and veterinary importance: A review. Parasitol. Res. 115, 23-34 (2016).

70. Benelli, G. Green synthesized nanoparticles in the fight against mosquito-borne diseases and cancer-A brief review. Enzyme Microb. Technol. 95, 58-68 (2016).

71. Madhiyazhagan, P. et al. Sargassum muticum-synthesized silver nanoparticles: An effective control tool against mosquito vectors and bacterial pathogens. Parasitol. Res. 114, 4305-4317 (2015).

72. Rajaganesh, R. et al. Fern-synthesized silver nanocrystals: Towards a new class of mosquito oviposition deterrents?. Res. Vet. Sci. 109, 40-51 (2016).

73. Vineela, D., Janardana Reddy, S. \& Kiran Kumar, B. Preparation, synthesis and characterisation of silver nanoparticles by fish scales of Catla catla and their antibacterial activity against fish pathogen, Aeromonas veronii. Eur. J. Pharm. Med. Res. 4, 537-545 (2017).

74. Company, R. et al. Effect of cadmium, copper and mercury on antioxidant enzyme activities and lipid peroxidation in the gills of the hydrothermal vent mussel Bathymodiolus azoricus. Mar. Environ. Res. 58, 377-381 (2004).

75. Maria, V. L. \& Bebianno, M. J. Antioxidant and lipid peroxidation responses in Mytilus galloprovincialis exposed to mixtures of benzo(a)pyrene and copper. Comp. Biochem. Physiol. C Toxicol. Pharmacol. 154, 56-63 (2011).

76. Yilmaz, R., Atessahin, A., Sahna, E., Karahan, I. \& Ozer, S. Protective effect of lycopene on adriamycin-induced cardiotoxicity and nephrotoxicity. Toxicology 218, 164-171 (2006).

77. Felix, R. et al. Review evaluating the in vitro potential of natural extracts to protect lipids from oxidative damage. Antioxidants. 9 , $231(2020)$.

78. Kong, X. H., Wang, G. Z. \& Li, S. J. Antioxidation and ATPase activity in the gill of mud crab Scylla serrata under cold stress. Chin. J. Oceanol. Limnol. 25, 221-226 (2007).

\section{Acknowledgements}

Dr. Anitha acknowledges the University Grant Commission (New Delhi, India), Project No. PDFSS-2014-15SC-TAM-10125. Financial support from the Ministry of Science and Technology of Taiwan (Grant no. MOST 107-2621-M-019-001, MOST 108-2621-M-019-003, MOST 109-2621-M-019-002 and MOST 110-2621-M019-001) and the Center of Excellence for Ocean Engineering (Grant no. 109J13801-51) to J.-S. Hwang is 
acknowledged. Grants from MOST to Tan Han Shih (Hans-Uwe Dahms) are gratefully acknowledged (MOST 107-2621-M-037-001, MOST 108-2621-M-037-001, and MOST 109-2621-M-037-001 to T.H. Shih). This work was supported partially by the Research Center for Environmental Medicine, Kaohsiung Medical University, Kaohsiung, Taiwan, from The Featured Areas Research Center Program within the framework of the Higher Education Sprout Project by the Ministry of Education (MOE) in Taiwan and by Kaohsiung Medical University Research Center Grant (KMU-TC108A01). A KMU-NPUST collaborative research grant is further acknowledged (NPUST-KMU-110-P010).

\section{Author contributions}

Conceptualization, K.M., and J.S. Data curation-R.R., D.D., P.A., and S.J. Formal analysis-M.V., S.J., J.A., and P.A. Funding acquisition, J.S.H. Investigation-M.V., J.S., and K.M. Methodology-K.M., J.S., and J.S.H. Project administration-K.M., J.S., and C.P. Resources software-R.R., D.D., J.S., A.T.A., and S.M. Supervision, K.M., L.W., J.S.H., and H.U.D. Validation, K.M., J.A., J.S.H., visualization, writing-original draft-K.M., J.S., M.V., C.P., and S.M. Writing-review and editing-K.M., L.W., H.U.D., J.S.H., A.D.M.A., C.P.

\section{Competing interests}

The authors declare no competing interests.

\section{Additional information}

Correspondence and requests for materials should be addressed to K.M. or J.-S.H.

Reprints and permissions information is available at www.nature.com/reprints.

Publisher's note Springer Nature remains neutral with regard to jurisdictional claims in published maps and institutional affiliations.

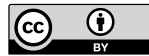

Open Access This article is licensed under a Creative Commons Attribution 4.0 International License, which permits use, sharing, adaptation, distribution and reproduction in any medium or format, as long as you give appropriate credit to the original author(s) and the source, provide a link to the Creative Commons licence, and indicate if changes were made. The images or other third party material in this article are included in the article's Creative Commons licence, unless indicated otherwise in a credit line to the material. If material is not included in the article's Creative Commons licence and your intended use is not permitted by statutory regulation or exceeds the permitted use, you will need to obtain permission directly from the copyright holder. To view a copy of this licence, visit http://creativecommons.org/licenses/by/4.0/.

(C) The Author(s) 2021 